\section{Resilience, resistance, infrapolitics and enmeshment}

\section{Philippe Bourbeau}

\section{Caitlin Ryan}

University of Groningen, Netherlands

\author{
University of Cambridge, UK
}

European Journal of International Relations $1-19$

(C) The Author(s) 2017

Reprints and permissions: sagepub.co.uk/journalsPermissions.nav DOI: $10.1177 / \mid 35406611769203$ | journals.sagepub.com/home/ejt

@SAGE

\begin{abstract}
A great deal has been written in the International Relations literature about the role of resilience in our social world. One of the central debates in the scholarship concerns the relationship between resilience and resistance, which several scholars consider to be one of mutual exclusivity. For many theorists, an individual or a society can either be resilient or resistant, but not both. In this article, we argue that this understanding of the resilience-resistance connection suffers from three interrelated problems: it treats resilience and resistance as binary concepts rather than processes; it presents a simplistic conception of resilient subjects as apolitical subjects; and it eschews the 'transformability' aspect of resilience. In a bid to resolve these issues, the article advocates for the usefulness of a relational approach to the processes of resilience and resistance, and suggests an approach that understands resilience and resistance as engaged in mutual assistance rather than mutual exclusion. The case of the Palestinian national liberation movement illustrates our set of arguments.
\end{abstract}

\title{
Keywords
}

Infrapolitics, Palestine, relationalism, resilience, resistance, substantialism

\section{Introduction}

A great deal has been written in the International Relations (IR) literature about the role of resilience in our social world. Resilience has been employed to examine the response

\footnotetext{
Corresponding author:

Philippe Bourbeau, Department of Politics and International Studies, University of Cambridge, 7 West Road, Cambridge, UK.

Email: pb623@cam.ac.uk
} 
of international institutions and regimes in the face of exogenous challenges (Hasenclever et al., 1997), to explain the actions and attitudes of individuals caught up in violent conflicts (Davis, 2012), to study societies' responses to new inflows of asylum seekers (Bourbeau, 2015a), to criticise liberal international intervention (Chandler, 2015), and to revisit critical security studies (Dunn Cavelty et al., 2015).

A facet of the literature that has attracted increasing interest lately — especially in critical theory-attuned scholarship - concerns the connection between resilience and resistance. Resilience is often contrasted with resistance, and many scholars consider the relationship between these concepts to be one of mutual exclusivity. We disagree. We contend that resilience and resistance are engaged in mutual assistance rather than mutual exclusion.

Part of the debate on this issue stems from the literature on the relationship between resilience and neoliberalism. Scholars attuned to Michel Foucault's (1991) governmentality thesis argue that resilience is a product of contemporary neoliberalism. For these scholars, beneath resilience lurks a dehumanising political agenda and the continuity of a state's dominance (Duffield, 2012: Walker and Cooper, 2011). For example, for Brad Evans and Julian Reid (2013: 14), resilience distinguishes between those who have the ability and the power to secure themselves from risk and those 'who are asked to live up to their responsibilities by accepting the conditions of their own vulnerability and asking not of the social'. Similarly, Jonathan Joseph (2013a: 51) contends that resilience is best understood in the context of 'rolling-out neoliberal governmentality'; he argues that current governmental policies of resilience constitute a strategy for states to abdicate responsibility in crises, thereby displacing the burden of responsibility from social institutions to the individual. As he understands resilience as a by-product of neoliberalism, Joseph predicts that resilience 'may well disappear as the language and techniques of governance change', and hopes 'that communities around the world ... will continue to show a lack of interest in the idea of being resilient. Better still, they might even show an interest in a much more inspiring French word - resistance' (Joseph, 2013b: 11).

In sharp contrast, Philippe Bourbeau (2015b) offers a broader socio-political view of the connections between resilience and IR, arguing that reducing resilience to a neoliberal product provides an incomplete and biased understanding of resilience in the context of world politics. Olaf Corry (2014) does not rule out completely the resilience-neoliberalism nexus, but underscores that resilience can be part of other governmentalities that deal with uncertainty and risk. From a slightly different angle, Peter A. Hall and Michele Lamont (2013) contend that resilience has been developed and strengthened as a societal response to the challenges provoked by neoliberalism. They employ social resilience to demonstrate that the capacity to adapt in the face of neoliberal governance is an essential characteristic of societies that advance collective well-being. Jessica Schmidt (2015) also contends that resilience is not necessarily a continuation of the neoliberal paradigm, but rather a response to its inherent frustrations and associated governance dilemma.

Several scholars from this latter camp have increasingly raised doubts about the deterministic viewpoint that Evans and Reid, as well as Joseph, present. The argument that communities should opt for resistance over resilience invites the obvious question: resistance to what? How exactly would a community 'resist' a catastrophic natural event 
such as a tsunami? Should communities opt for resistance to state counterterrorism programmes, to terrorism itself or to neoliberal governance or youth radicalisation? Is resilience a by-product of neoliberalism in all locations, places, cultures and expressions? Has neoliberalism permeated and contaminated the full set of behaviours of social groups and individuals around the globe (from those living in an isolated Tanzanian village, to those on the Peruvian coast, to those in some particular neighbourhoods of Birmingham, UK) with the same strength and comprehensiveness?

These questions are important and remain unanswered. The present article, however, raises a complementary set of concerns. We argue that conceptualising resilience and resistance as mutually exclusive reflects a substantialist ontological position rather than a relationalist one. Substantialism postulates that entities exist prior to their relations with other substances, a position that allows scholars to identify these fixed entities as primary units of analysis in research. In sharp contrast, relationalism posits that entities gain their meaning through their processual relations with other entities. Entities shape and are shaped by the dynamic and ever-changing relations among entities. Obviously, the expressions of the relationships between resilience and resistance can take several expressions and forms, including a sequential relation in which resilience strategies would lead to resistance (and vice versa). Yet, the focus of this article is on what precedes an analysis of the forms of relationship. We believe that it is essential to first debate how the interconnections between resilience and resistance are approached and studied before embarking on an analysis of the particular forms that the relationship might take.

When approached from a relational perspective, the current literature on the resilience-resistance debate appears to suffer from three (substantialist-attuned) problems. First, the current literature treats resilience and resistance as binary concepts rather than processes. Second, it presents a simplistic understanding of resilient subjects as apolitical subjects. Third, it eschews the renewal and transformational aspects of resilience.

In a bid to resolve some of these issues, we put forward two propositions. First, we postulate that by conceptualising the zones of contact between resilience and resistance from a relational perspective, we can move the scholarship away from an understanding of the two concepts as competitive and mutually exclusive. The relational approach opens up our perspective on the processes of resilience and resistance. Second, we suggest that resilience and resistance are engaged in mutual assistance rather than mutual exclusion. We contend that the dynamic and fluid processes of resistance and resilience are so enmeshed that treating them as mutually exclusive entities makes little sense; on the contrary, analysing them via instances of connections and mutual assistance is a more fruitful research path.

Our call to highlight the mutual assistance between resilience and resistance instead of their mutual exclusivity does not mean that we are treating these concepts as synonymous. We concur with the largely accepted definition of resilience as the process of seeking to maintain or transform a referent object in the face of exogenous and endogenous shocks, and of resistance as organised and principled contestation of power and domination.

The body of this article is organised as follows. The first section opens with a theoretical critique of the substantialist position, which is followed in the second section by a discussion of our proposal for a relational understanding of resilience and resistance. The third section illustrates the preceding set of arguments through an analysis of the case of the Palestinian national liberation movement. Our concluding remarks sum up our argument. 


\section{Entities, mutual exclusiveness and problems}

This article builds on Mustafa Emirbayer's (1997) distinction between substantialism and relationalism in social theory and on Patrick T. Jackson and Daniel Nexon's (1999) application of this distinction to world politics, followed more recently by Ole Jacob Sending, Vincent Pouliot and Iver Neumann's (2015) edited book. Substantialism postulates that substances or entities (such as states) should serve as units of analysis in research and that the existence of such entities precedes interaction. Substantialism takes two forms: self-action substantialism posits that things or substances act under their own powers while interaction substantialism argues that substances remain fixed and unchanging throughout their interaction with other entities. For a substantialist, 'entities are already entities before they enter into social relations with other entities ... units come first, like billiard balls on a table, they are put into motion and their interactions are the patterns we observe in political life' (Jackson and Nexon, 1999: 292).

In contrast, relationalism posits that relations make the world hang together, to paraphrase John Ruggie (1998). For relationalists, the dynamic and ever-changing relations among elements are the appropriate units of analysis in research. Relationalism postulates a processual understanding of our social world: entities or substances acquire their meaning and significance through their transactions and relations with other entities or substances; the relations are seen as constitutive of the entities. For Sending et al. (2015: 7), 'agents, objects, and structures emerge from transactions and connections, that is, relations'. As several relationalists highlight, Norman Elias's example (quoted in Emirbayer, 1997: 283) of wind nicely illustrates this point of view: 'We say, "the wind is blowing", as if the wind were actually a thing at rest which, at a given point in time, begins to move and blow. We speak as if a wind could exist which did not blow.'

Obviously, the expressions of the relationships between elements can take several forms. In the context of this article, we might consider, for example, a sequential understanding of the relationship between resilience and resistance in which prolonged acts of resistance in the face of a series of disturbances would lead to the necessity of developing resilient strategies. Alternatively, we might pursue the opposite approach and propose that expressions of resilience can be observed right after a shock and before strategies of resistance are deployed. Yet another potential avenue would be to study the triangular relationship among resilience and resistance and other concepts, such as vulnerability, trauma and traumatic memories, and path dependence — to name just a few. ${ }^{1}$

Important as these questions are (and we believe that they will inform much of the literature for some years to come), our argument precedes an analysis of the particular form that the relationship between resilience and resistance takes. We postulate that before digging deeply into the particular forms that the relationship between resilience and resistance takes and investigating how resilience and resistance relate to other concepts, scholars need to think about how the interconnections between resilience and resistance should be approached and studied. Specifically, we believe that it is essential to first debate whether resilience and resistance gain their meaning in isolation as fixed entities or through their processual relationship with one another.

From this relational perspective, we problematise the conceptualisation of resilience and resistance as distinct entities that are mutually exclusive. In particular, three major 
substantialist-attuned problems arise. First, the literature treats resilience and resistance as binary concepts rather than as processes. For many IR scholars, a given society (or individual) either is resilient or is not. Similarly, the same society either is engaged in acts of resistance or is not. The unit of analysis in each case (i.e. resilience or resistance) is fixed and unchanging. Evans and Reid (2013: 85) encapsulate an understanding of resilience and resistance as fixed and mutually exclusive entities when they posit that resilient subjects are 'subjects that have accepted the imperative not to resist'. For them, a resilient subject is a subject that cannot 'conceive of changing the world, its structure and conditions of possibility' (Evans and Reid, 2013: 85). If our world is now in a constant state of emergency, Mark Duffield (2012: 481) argues, 'then resilience has become a monotonous characteristic of everything'. Resilience is treated as a totality, as a fully formed strategy of governance. In addition, many scholars hold that resilience and resistance, as units of analysis, act under their own power. For Joseph (2013b: 262), 'the idea of resilience does two things. It supports the organisational structure of the advanced liberal societies' and 'it supports the idea of an individual neoliberal subject'. Similarly, resilience possesses its own 'logic', according to Filippa Lentzos and Nikolas Rose (2009: 243). That is:

a systematic, widespread, organizational, structural and personal strengthening of subjective and material arrangements ... [that] aspire to create a subjective and systematic state to enable each and all to live freely and with confidence in a world of potential risk.

Resilience and resistance are thus seen as a one-size-fits-all concept - a rather surprising attitude given that one of the greatest strengths of the critical theory tradition in IR is its willingness to embrace the complexity of our contemporary social world, to shy away from deterministic and totalising standpoints, and to reject an oversimplifying representation of world politics.

Second, some scholars view resilient subjects as apolitical subjects that cannot participate in changing the world, but must accept the constraints imposed on them as a condition of the social world. Evans and Reid (2013: 85) contend that 'the real tragedy for us is the way the doctrine [of resilience] forces us to become active participants in our own de-politicisation'. A narrow substantialist conceptualisation of resilience is implied when the resilience literature frames 'resilient subjects' as apolitical since they are subjects upon whom resilience is imposed. Within this logic is the contention that resilience is something that is brought about as a result of a 'resilience-building' project, or in the service of neoliberal governance. As argued by Bourbeau (2015b: 379), this 'makes the mistake of equating a particular government's use of resilience with the concept of resilience'. In focusing on how governments have recently deployed resilience as a tool and concept, there is a risk that the myriad forms that resilience takes are subsumed. Further, the privileging of the state through implying that it is the state that is 'making' resilient subjects makes it extremely difficult to 'see' the agency of subjects who can be resilient, but who may also be more than exclusively resilient.

There is an important critique within the literature that problematises the resilience approach for facilitating the adjustments to a given situation/shock without challenging the underlying conditions that make it necessary to adjust. For example, one can clearly 
see the problem with a 'resilience-building' programme that tries to make the poor 'adaptable' to the effects of poverty, and, in so doing, ignoring the root causes (Hillier and Castillo, 2013; Walklate, 2011). However, in such a case, it is also important not to overlook that the 'resilient subjects' may fully comprehend the root causes of their own subjugation. While coping and adapting to the symptoms, they may also be engaged in resistance to the underlying causes, or to the 'resilience-building' itself. As mentioned earlier, Evans and Reid (2013: 85) argue that the resilient subject has 'accepted the imperative not to resist'; however, this reflects an understanding of resistance as underpinned by a state-centric logic of resistance. In this context, treating resilience and resistance as opposing forces results in a reductive view of a society's/individual's available choices: since you cannot be both resilient and resistant to states' policies, being resistant is thought to be the best strategy. James Scott (1985), in contrast, argues that subordinate groups usually fully understand the material and ideological conditions of their subordination. While they may not engage in overt revolt, they are also unlikely to fully adopt the hegemonic ideology responsible for their subordination. Such examples of refusal to acquiesce are not easily seen from a top-down or state-centric view, which is why we argue that greater attention must be paid to the complementarity between resilience and resistance, and the instances wherein resilience is a condition for resistance.

Third, many scholars eschew the renewal and transformational aspects of resilience. Resilience is not only about maintaining the status quo (of an individual's or a society's way of life), but also about transforming and remodelling an individual or social structure. The transformational aspect of resilience implies the introduction of novel vectors of response that will (implicitly or explicitly) change existing policies and set new directions for governance in this field (Bourbeau, 2013).

Scholarship in disciplines for which resilience is a central concern has highlighted, consistently and for many years, the transformational nature of resilience. In psychology and in social work, pioneers of resilience studies have highlighted that resilience 'involves the potential for personal and relational transformation' (Walsh, 2003: 3), noting that resilience is about bouncing back as well as bouncing forward (Sleijpen et al., 2013; Walsh, 2002). Many have equally underscored that resilience, as a dynamic process, comprises some level of transformation and reconfiguration (Lepore and Revenson, 2006; Luthar, 2003; Masten and Cicchetti, 2016; Rutter, 1987). In ecology, several leading figures have pointed out that transformability is an integral part of resilience; consider, in this vein, Brian Walker et al.'s (2004) seminal article, 'Resilience, adaptability and transformability in social-ecological systems', Carl Folke's (2006: 262) remark that 'there is an increased emphasis on transformability' in resilience studies, and Boyd and Folke's (2011: 266) postulation that resilience is, in part, about 'innovating and sowing the seeds of transformation'. Accepting the renewal and transformational aspects of resilience does not mean that one has to accept psychology's normative tendency to treat resilience as inherently positive or ecology's assumption of equilibrium; indeed, scholars have theorised the transformational aspect of resilience without reverting to either an equilibrium-based or a priori normative stance (Berkes and Ross, 2013). Furthermore, even though IR is a latecomer to resilience studies, some have already pointed out that resilience is about persistence and transformation (Edwards, 2015; Malkki and Sinkkonen, 2015). 
It is unclear why and for what purpose IR scholars ignore these vast swathes of literature on resilience. Certainly, though, the consequence of this choice is obvious: ignoring the renewal aspect of resilience solidifies the substantialist position of treating resilience as fixed and unchanging. By eschewing the relational nature of resilience, scholars not only isolate themselves analytically, but also limit themselves from entertaining points of contact between resilience, resistance and contemporary politics.

\section{Contestation, infrapolitics and enmeshment}

In a bid to resolve some of these issues, we put forward two propositions. First, we postulate that understanding the processes of resilience and resistance from a relational perspective can move the scholarship away from a default understanding of the two processes as competitive and mutually exclusive. We place the relationship between resilience and resistance within the rubric of infrapolitics and hypothesise each process as a strategy for contesting a situation that is deemed inappropriate. Since, in our understanding, resistance and resilience are not inherently competing concepts, they can be brought together to examine how a given situation is politically debunked and contested. As mentioned earlier, the focus here is not on the actual form that the relationship between resilience and resistance takes (e.g. sequentiality), but rather on the idea that the meaning of both resilience and resistance is acquired and evolves through the relationship between the two concepts.

Second, the strategies and experiences of contestation demonstrate slippage and interaction between resilience and resistance. Resistance and resilience can assist and support one another. In broader terms, adopting a more inclusive approach allows us to appeal to both resilience and resistance as tools for understanding certain features of world politics. Embracing this shift in focus allows our analytical framework to give much greater credit to populations/communities/individuals who cope during chronic adversity or protracted conflict.

The concept of infrapolitics helps to demonstrate how resilience and resistance are relational rather than mutually exclusive because the form each takes shapes and is shaped by the other. According to Scott (1990), infrapolitics describes the ways in which subordinate groups can continue to wage a struggle against their subordination, but in a way obscured from the view of the dominant power. Scott (1990: 183) goes on to point out: 'That it should be invisible, as we have seen, is in large part by design - a tactical choice born of prudent awareness of the balance of power.' It is crucial to note that infrapolitics provides the foundation upon which other, more visible, resistances rest. Scott initially observed infrapolitics in the rice-growing Malaysian village of Sedeka during the Green Revolution (Scott, 1985). He observed the ways in which the poor of the village, and especially the poor with very small landholdings, had to adapt to and adjust their farming in the context of the rise of combine harvesters and the decline of available land to rent. Here, resilience and resistance are not mutually exclusive, but rather mutually assist each other. The resilient strategies of Sedeka's poorest farmers shape the form that resistance can take, but it does not exclude their resistance to the effects of the Green Revolution. Their material conditions necessitated profound adjustments to ensure the endurance of their daily life and limited their ability to engage in 
open revolt, and, at the same time, their engagement in infrapolitics of resistance supported their capacity to continue farming.

The farmers demonstrated traits easily characterised as 'resilient' as they were faced with numerous shocks and rapid changes to their material environment and economy. They adapted their agricultural and economic habits to the rapidly changing reality in their village. At the same moment that they were adapting to their new reality, they engaged in a sustained infrapolitics of resistance to it, which challenged the social legitimacy of the village rich, who were profiting from the Green Revolution. The village poor did not engage in open revolt, but they did find ways to make their challenge to the Green Revolution known to the rich, such as through false deference, pilfering, slander or evasion (Scott, 1985). Engagement in this infrapolitics of resistance helped poor farmers to adapt to the rapid change to their material conditions, but, in turn, these adjustments do not imply agreement. First, acts of resistance such as pilfering did produce some (albeit small) actual material gain that could increase the ability of poor farmers to adjust to the disturbances. Second, the poor farmers' adaptation does not 'confound what is inevitable with what is just' (Scott, 1985: 317). Slander, for example, provides an example of resistance to the social conduct of members of the ruling class. When the poor of Sedeka identify behaviours that violate the social norms of generosity and fair treatment, character assassination/slander of the perpetrator represents a form of resistance to the changes in social practices brought about by the Green Revolution (Scott, 1985: 235). Adapting strategies to the 'inevitable' change of the Green Revolution does not mean that the poor farmers of Sedeka are willing to see it as just, and so they engage in the forms of resistance most conducive to their material and social conditions, their need to survive, and their ideological refusal to fully submit to their 'fate'. The result is that infrapolitics in Sedeka is shaped by the material and social conditions of the Green Revolution, the ideology of the poor and the basic need to adapt and maintain a 'certain' way of life.

Having put forward our arguments for a relational approach to resistance and resilience, we also defend a second, more controversial, contention: we suggest that, on some occasions, resistance and resilience engage in mutual assistance. Our contention is that the dynamic and fluid processes of resistance and resilience are so enmeshed that treating them as mutually exclusive, fixed entities makes little sense. Instead, we propose that an analysis that takes into account the mutual entanglement of resilience and resistance will be more fruitful. It is through this mutual assistance that expressions of resilience and of resistance gain their meaning and importance.

Resistance is an extremely demanding course of action, with numerous impediments and difficulties. Not only can resistance require months, years and even decades of struggle, but setbacks and obstacles often accompany every gain. Resistance, then, is itself a processual path paved with disturbances and turbulences. As a result, the process of resisting — and especially of resisting against one of the most powerful political organisations in the history of humankind (i.e. the state) - is a course of action that, by its very nature, demands resilience to ensure its continuity. Seen in this light, resilience, rather than a mere annoying noise in the ears of resistance, becomes a crucial vector for explaining why some resistance movements manage to persevere despite heavy hurdles and setbacks, and while others do not. Resilience demands extraordinary acts of willpower, 
dedication, determination, resourcefulness and creativity — all traits that can be deployed in furtherance of strategies of resistance.

Where the substantialist standpoint sees resilient subjects as apolitical, we contend that a resilient subject (or society) can be neither apolitical nor politically passive. To seek to maintain a perceived status quo in the face of disturbance is inherently a highly political move, just as it is a highly political and deeply active move to adjust to change by seeking to transform a policy. As mentioned earlier, resilience is the process of seeking to maintain the status quo in the face of shocks, but it also refers the idea of transforming a referent object. As such, communities developing strategies to adjust to difficulties are also potential sites of resistance to the structures, inequalities or injustices that have necessitated these adjustments. Enacting resilience can mean that you find a way to 'get on' with daily life without acquiescing to the political, economic or social situation that you are in. In situations that necessitate that you 'get on' with daily life and adapt to stress, and particularly in contexts of protracted conflict or structural upheaval, communities or individuals may engage in resistance that is assisted by resilience (Ryan, 2015).

Writing from within the literature on non-violent resistance movements, Kurt Schock $(2005,2013)$ argues that the success of civil resistance relies, in part, on resilience. This is also expressed by Erica Chenoweth and Maria Stephan (2011: 10), who see resilience as one 'mechanism necessary for success'. In the context of Colombian civil resistance to state and non-state (National Liberation Army) violence, Annette Idler et al. (2015: 157) found that resilience was a positive characteristic of communities in the Samaniego region, which helped contribute to their successes by keeping resistance alive during difficulties. Discussing resilience in the context of longer-term interactions between movements and adversaries, Schock (2005) argues that resilience was highly important in the success of civil resistance movements in South Africa, the Philippines, Nepal, Thailand and Poland, and that a lack of resilience in Burma and China was an inhibiting factor in the movements' success. In this sense, resilience can assist resistance strategies. This is especially true for a resistance movement that endures for a long period of time, and therefore faces numerous attempts by its opponents to quash or undermine it. This might be seen as a form of sustained infrapolitics of resistance that relies on and is assisted by resilience.

One might add that our argument of mutual assistance could be pushed further to encapsulate situations in which resilience becomes the mode of resistance, in which resilience subsumes resistance. In the context of civil resistance movements, the adversary (usually, but not always, the state) seeks to eliminate or disempower the movement. In situations where the threat is defined and framed as a threat to coping itself, resilience may represent resistance insofar as it constitutes a counter-challenge to the adversary's attempts to squash the movement or to make the idea of living in one area so intolerable that individuals/communities seem to have no other choice but to leave the area. Staying and seeking to maintain a 'normal' life might, in fact, be a mode of resistance. ${ }^{2}$ To be sure, these hypotheses are important and evaluating them would push the study of the relationship between resilience and resistance many steps forward. Yet, we believe that it is beyond the scope of the article to investigate the varied forms that the relationship between resilience and resistance might take (e.g. sequentiality or subsumption). If anything, these hypotheses highlight the importance of investigating how the relationship 
between resilience and resistance should be approached and studied before seeking to lay out, catalogue and discuss the full range of potential forms.

\section{Resistance and resilience in action: The Palestinian national liberation movement}

The most obvious example of where resilience and resistance acquire meaning through each other is within the Palestinian national liberation struggle. Internal Palestinian discourses and narratives about armed resistance and unarmed resistance have shifted and morphed throughout the duration of the Palestinian national struggle (Pearlman, 2014). At the height of the Second Intifada, popular support for armed resistance was at its peak, due to a wide variety of factors that have been documented elsewhere (Abufarha, 2009). Although there have been several periods of open revolt by Palestinians, such as the First and Second Intifadas or the violent conflict between the Palestine Liberation Organization (PLO) and Israeli forces during the Lebanese civil war, the majority of the years between 1948 and today have been characterised more by resilience and an infrapolitics of resistance than open revolt. Within the Palestinian context, resilience is complementary and relational to overt resistance.

Furthermore, resilience is used by 'ordinary' Palestinians to sustain daily life. In the context of the unpredictable and ever-changing occupation of the Palestinian territories, Palestinians must be flexible and adaptive in their daily lives, such as when crossing new 'flying' checkpoints or finding ways to access economic opportunity amid closure and restriction. They must also demonstrate traits of endurance and perseverance in order to maintain the hope of Palestinian liberation amid the ever-increasing Israeli settlements in the West Bank and East Jerusalem. Overt revolt against one of the most well-armed militaries in the world would have been impossible to sustain for 68 years. During multiple periods where the leadership of widespread resistance has been fractured, or absent, resilience has been a necessary tactic of the Palestinian population, especially in the context of an occupation that has changed over time. The continuation of a Palestinian liberation movement for that period illustrates how resilience is necessary to sustain resistance through its ebbs and flows over decades. Adaptation and flexibility are necessary to 'get on' with daily life and to survive the occupation, while perseverance and endurance are necessary to maintain hope for the future in the midst of situations that may appear 'hopeless', such as the recent wars in Gaza or the disappearance of land for a viable Palestinian state.

Palestinians have a word to describe their adaptation, coping and perseverance: sumud. Sumud translates as 'steadfastness' or 'resilience', and it is a word commonly used by Palestinians to explain how they continue to live under occupation. The existing literature on sumud argues that it describes the daily-lived practices of Palestinian resilience under occupation, as well as functioning as a social practice that Palestinians can reference as one of their defining traits (Halper, 2006; Hass, 2002; Richter-Devroe, 2011; Singh, 2012).

Pearlman (2014) situates the emergence of sumud in Palestinian discourse during the late 1970s/early 1980s. During this period, while the PLO was 'in exile' (first in Jordan, and then in Lebanon), the Israeli Civil Administration in the West Bank passed hundreds of military orders to 'govern' Palestinians. Political activism was severely punished, with 
house demolitions, administrative detention and curfew. During this time, the PLO encouraged Palestinians to remain resolute by focusing on sumud (Pearlman, 2014: 9596). When opportunities for organised political struggle were constrained by the nature of the occupation, sumud was framed and encouraged as a means of resistance that Palestinians could enact when they 'stayed put' on their land. This is also reflected in the popular Palestinian sentiment that 'to exist is to resist'. When discussing sumud in interviews, women frequently expressed that to stay in their homes was sumud:

Sumud means that we should, even if it is difficult, stay. This is our land. Where to go? We don't know America or Australia. This is my land. I know that I am from Bethlehem. I am Bethlehemian people. And my roots are here, my parents, my grandparents, so I should stay. I keep telling my children the same. Even with all these difficulties we can. ${ }^{3}$

Sumud is an authentic Arabic word. You know? It represents the steadfastness of the Palestinian people. And it represents also the will of keeping the community, the Palestinian community, safe. And to reduce emigration, and you know. ${ }^{4}$

We resist in, uh, in our way of living, let's say. In our resilience. In our being here, refusing to emigrate, this one thing. Encouraging our children to stay here, and study here and work here. Staying in Palestine, enduring all the difficulties that we mention, the lack of freedom, the restrictions placed upon us, the wall, not going to Jerusalem, this is resilience, this is sumud, what we call sumud. ${ }^{5}$

For these women, staying in Palestine despite hardship and keeping one's home and land is one way of acting with sumud. One can also act with sumud in other ways, such as through the reproduction of Palestinian culture. Sumud, in this sense, reflects action, but there is also a great deal of space within the definition of sumud for it to be used differently by different people: 'Sumud is not only about being in a place, it's a journey or a process. Sumud is not static, it is action, life' (Palestinian peace activist, cited in Van Teeffelen, 2011: 41). Here, sumud is not only a trait, but also a self-reaffirming practice that is relational - how one enacts it depends on one's own circumstances, as well as the broader circumstances of the Palestinian national struggle.

There is some debate in the literature over whether sumud is a form of resistance. On one side of the debate, Amira Hass (2002) contends that sumud is not a form of resistance, and Rashmi Singh (2012) suggests that sumud is 'passive' resistance. We, and other scholars, stand on the other side and argue that sumud is, in fact, a form of resistance. Sophie Richter-Devroe (2011: 33; see also Halper, 2006) frames sumud as 'a form of infrapolitics, or everyday resistance'. Following the logic of our argument in this article, sumud as resilience is engaged in mutual assistance with resistance. This builds upon the work of Caitlin Ryan (2015), who suggests that sumud is a form of 'resilient resistance'. While Palestinians frequently refer to sumud as a sort of national trait, it also functions in the form of daily-lived practice, which takes the form of adaptation to the shocks and unpredictability of the occupation. In the context of the ever-shifting occupation, one can frame one's daily activities as sumud, particularly when those daily activities aim to make life 'normal' in the context of the 'abnormal' occupation. Resilience and resistance acquire meaning through each other in practices of sumud. 
One example of such adaptation can be seen in the high proportion of women who have taken up previously 'male' roles as breadwinners and heads of household. A substantial share of the male population has spent time in prison. The numbers of men in prison were particularly high during the First and Second Intifadas (Pearlman, 2014). As a result, women bear increased responsibility for generating income and maintaining the family. This represents adaptation of daily-lived practice and of perceived gender roles, and hence a form of resilience necessary to 'get on' with daily life. Women whose husbands are in jail have to adapt to changed circumstances, and can frame these adaptations as a form of resistance. Such resilience does not exclude the possibility of resistance, but instead supports the 'overt' resistance of the broader national liberation movement by ensuring the continued functioning of social and communal networks. Furthermore, given that Palestinians in Israeli prisons are seen to be 'political prisoners', the adaptation and coping of their family members is more easily framed within a logic of resistance to the occupation. In narrative interviews conducted in the West Bank, women frequently discussed how they found ways to adapt to seek to maintain the status quo while their husbands were in prison ${ }^{6}$ :

After my husband was arrested and put in jail, I had to work. I found work in a Palestinian nursery school, working with children. We were building our home at the time. With the small salary I earned, I continued to have work done on the house. So he spent the eight years in prison. ${ }^{7}$

The occupation disrupts daily life and restricts freedom both within and outside of the occupied Palestinian territories. A complex and ever-evolving system of checkpoints, the separation wall, settler-only roads and settlement boundary areas disrupt and interrupt freedom of movement (Parsons and Salter, 2008; Weizman, 2007). These disruptions can be short-term, such as in the case of 'flying' or temporary checkpoints, or they can be more long-term, such as in the case of the separation barrier. These disruptions have to be negotiated in one's daily life, depending on the context in which they are located. For example, the path of the separation barrier diverges considerably from the 1949 Armistice line, creating what is referred to as the 'Seam Zone'. In some places, the barrier cuts Palestinian communities off from the rest of the West Bank, enclosing them on the 'Israeli side' of the barrier. Maintaining access to other Palestinian communities, friends and family, as well as to goods and services, requires a continuing process of access negotiation, in the form of applying for permits and using access gates. The 'normalcy' of daily life in these communities may include only being able to come and go at predesignated times when the access gates are open, or having to apply for permits to have friends and family to visit.

When it comes to an access and permit system that designates what time you can or cannot enter your community, adaptation to the disruption of daily life does not imply acquiescence. One might expect that under such circumstances, individuals change and alter their daily schedules to ensure that they are home before the access gates are closed for the night, or that applications are filed for visiting family members well in advance of celebrations or holidays. People subjected to such a system of access restrictions will make necessary adaptations and adjustments to their schedules in order to facilitate a 
degree of 'normalcy' in their daily lives. However, such adaption should not be taken as a sign that Palestinians in the Seam Zone have 'given in' to the occupation, and these adaptations help give meaning to Palestinian definitions of resistance. According to Laleh Khalili (2007: 225):

the efficacy of sumud is not in its ability to beget political cataclysms, but rather in its cumulative force over decades resulting in incremental changes, which may not substantially alter societies, but which provide a breathing space for those who are most often trampled in the stampede of history.

Sumud opens up space for strategies of adaptation and coping to be framed as resistance to the occupation so that one's adaptation is not to be confused with acceptance.

The attempts of Palestinian women to make life 'normal' for their children also illustrate resilience in the context of the occupation. As a tactic, sumud functions in the realm of the 'everyday' through attempts to make life under occupation 'normal' despite the stress and struggle (Richter-Devroe, 2011; Ryan, 2015). The occupation disrupts daily life and restricts freedom both within and outside of the occupied Palestinian territories. One example of disruption faced by children comes during 'night raids', wherein the Israeli army enters a home or a series of homes within a village. During these raids, children are awoken and photographed. In some villages, such as Nabi Saleh, these raids are frequent and the children are photographed repeatedly, even if the army has recent photos of all the children in the house. Families report that even babies and toddlers are photographed. Women whose children experience this type of disruption on a semi-regular basis seek to make their children's lives as 'normal' as possible as a means of adjusting to these disruptions. However, attempts to make daily life under 'occupation' normal should not be read as acceptance of the occupation:

It's a problem to say that it's [the occupation is] normal, because it's not, and it shouldn't be. At the same time, it's a problem not to say it's normal, because if we don't say it's normal and try to live it, it will devastate us, and break us. ${ }^{8}$

Richter-Devroe found similar sentiments among her research participants, who claimed that 'getting on' with life and trying to find ways to be happy and 'normal' are essential to deal with and live under occupation. In her case study of women who travel around the West Bank or East Jerusalem during their free time, Richter-Devroe (2011: 38) found that the women saw their day trips as a 'their right to have fun and relax in life'. This affirmation of a right to have fun and enjoy one's life does not imply acquiescence to the occupation, as the women also framed their travelling as a 'form of defiance against Israeli control' (Richter-Devroe, 2011: 40). Here, again, resilience and resistance are in mutual assistance insofar as Palestinians frame their resilience as a form of resistance at the ideational level.

Daily struggles to secure adequate water also represent the adjustment necessary to make life 'normal' throughout the West Bank. Access to water is strictly controlled by Israel, and $80 \%$ of the water pumped from aquifers in the West Bank is distributed to Israelis - either in Israel or in settlements (Amnesty International, 2009). Palestinians 
living in 'Area C' — particularly Bedouins — are prevented from connecting to a water supply, and, as a result, they live on less than 20 litres of water per day, considered by the World Health Organization to be a crisis level (UNOCHAOPT, 2012).

Water shortages were evident during the stay of one of us in the West Bank. Twice over a six-week period, the family that Caitlin lived with 'ran out' of water, the result of the water supply being turned on for only a few hours per week and the storage tanks on the top of the house running dry (B'Tselem, 2000). In one interview, a woman living in a small village explained how access to water was an important element of how the occupation affects daily life:

Even water, we have a problem with water, we only have water 12 hours per week, so, ah, for the 12 hours, we have to fill the water tanks on the roof so we can make sure we have water for the rest of the week. The settlers are enjoying our water $24 / 7 .{ }^{9}$

The example of access to water demonstrates only one element of how the occupation seeps into daily life, and how it presents Palestinians with pervasive problems that they must deal with and adapt to. As with the example of the travelling women from RichterDevroe, women framed their adjustment to water shortage as resistance to or defiance of the occupation forces. In this sense, one's ability to cope with living under occupation may be strengthened by one's ability to frame that coping as a form of resistance. 'Dealing with' the situation may not change the reality of the occupation, but it certainly changes the way occupation is experienced, reflecting the sentiment of the research participants in Nabi Saleh who stated that the occupation would 'break' them if they did not try to make life 'normal'. ${ }^{10}$

Palestinian resilience to the daily impacts of the occupation is relational to Palestinian resistance to occupation. The forms of Palestinian resilience interact with and shape the forms of resistance that are possible, and, in turn, Palestinian resistance and refusal to acquiesce makes resilience necessary because (overt) Palestinian resistance is almost invariably met with a Israeli response that makes daily life more difficult. This can be seen within the interactions between resilience and resistance in the weekly demonstrations against the annexation of village land and village springs in the village of Nabi Saleh and other Area $\mathrm{C}$ villages. Land annexation in the occupied territories is most common in Area C, particularly in places in Area $\mathrm{C}$ adjacent to Israeli settlements or near the separation barrier. Since the end of the Second Intifada, a common tactic of Palestinian resistance to land annexation has been weekly demonstrations organised by non-violent, non-partisan, village committees. Villages such as Budras, Nabi Saleh, Bil'in and Nil'in are particularly well known as sites of weekly demonstrations against the loss of village land and against the wider occupation as a whole (Richter-Devroe, 2011). These demonstrations are organised within the village, but they also attract participants from other parts of the West Bank, and activists from Israel and around the world. As such, these weekly demonstrations clearly represent an example of Palestinian resistance to the occupation. However, these demonstrations also make resilience necessary.

These demonstrations generate an Israeli response, both formal, from the Israeli Defense Forces (IDF), and informal, from Israeli settlers. These responses require Palestinians to adapt to adverse conditions. Human rights organisations such as B'Tselem 
and $\mathrm{Al} \mathrm{Haq} \mathrm{have} \mathrm{documented} \mathrm{violent} \mathrm{reactions} \mathrm{to} \mathrm{the} \mathrm{demonstrations} \mathrm{by} \mathrm{the} \mathrm{IDF} \mathrm{and} \mathrm{by}$ armed settlers. For example, the IDF uses tear gas, rubber bullets, live ammunition and 'skunk water'"11 to disperse demonstrators. Since 2008, the IDF has killed multiple demonstrators with projectiles, such as Mustafa Tamini, killed by a tear gas canister fired from close range in Nabi Saleh in December 2011 (Al Haq, 2011). Residents of Nabi Saleh also report that the IDF frequently enters the village during Friday demonstrations and fires tear gas and skunk water directly into people's houses (Al Haq, 2011). These violent responses necessitate that residents in demonstrating villages adjust to and deal with unpredictable shocks. For example, women responsible for cleaning their homes have to find ways to clean up skunk water fired into their windows. Women with small children must find ways to carry on with the security risk posed to their children by weekly incursions of the IDF into the village. These, and other related, situations that necessitate resilience are the result of the village's participation in overt resistance.

Overall, the daily-lived experiences of this structural and physical violence require Palestinians to adapt to changes to their physical landscapes and daily routines. In turn, their ability to reflect upon and draw strength from their ability to adjust to these disturbances, and the continued necessity of doing so because of the occupation's endurance, helps to reinforce their resolve to engage in national resistance. Resilience, as demonstrated in the context of the Palestinian national liberation movement, can provide a condition for resistance, and within daily-lived practice in the occupied territories, there is mutual assistance and intertwinement between resilience and resistance. As such, this demonstrates the importance and added value of thinking about resilience and resistance in relational terms instead of in substantialist terms. Rather than understanding resilience and resistance as fixed entities that exist prior to their relations, our case study underscores that the form each concept takes shapes and is shaped by the other concept. Not only are resilience and resistance not mutually exclusive, but each concept also acquires meaning and significance through its relations with the other concept.

\section{Conclusion}

A relational approach to resilience allows us to account for the wide variety of forms that resilience can take - even within one context, such as Palestine, where there are multiple ways in which one can act with resilience. These different ways of acting with resilience in Palestine have changed over time depending on factors such as the strength of national-level leadership, the structure of Israeli control over the occupied territories or the viability of the peace process.

Although we focused on the case of the Palestinian national liberation movement, we believe that our conclusions might apply to other instances of subjugation. Lived experiences of subjugation vary from person to person, as well as temporally, necessitating a variety of forms of resilience. Resilience itself is highly relational because one's adjustment strategies are structured by the context, material conditions and existing relations of power — resilience is not static by nature because it relies on adaptation and flexibility. Since it is a response to shocks that are on some occasions unpredictable, it does not take one homogeneous form, but rather responds to the situation at hand. Its relationship to resistance is therefore also not static by nature or predetermined, but adaptive and heterogeneous. 
Resilience (as well as resistance) can be shaped by conditions of subjugation or hardship, by material need, or, as Scott (1990) points out, by the level of indignation.

Furthermore, attempts to adjust to a shock by seeking to bounce back to an established way of life or to maintain a previous status quo can provide/sustain conditions for more overt resistance - the success of social and resistance movements over time depends on the adaptation strategies of the movements themselves, as well as of the populations who offer support for the resistance movements. According to Scott (1990: 191-192), in reference to the infrapolitics of resistance:

One might argue perhaps that even such practical resistance, like the discourse it reflects and that sustains it, amounts to nothing more than trivial coping mechanisms that cannot materially affect the overall situation of domination. This is no more real resistance, the argument might go, than veiled symbolic opposition is real ideological dissent. At one level this is perfectly true, but irrelevant since our point is that these are the forms that political struggle takes when frontal assaults are precluded by the realities of power.

A relational understanding of resilience allows for a better understanding of how material conditions and relations of power may require populations or specific resistance movements to demonstrate resilience in order for resistance to continue. In order to withstand shocks, as well as pervasive repression, populations and resistance movements alike must be able to adapt strategies and tactics of resilience in order to maintain resistance over long periods of time. As demonstrated by Scott, there will be moments in the life of any resistance movement where overt resistance is impossible. During these times, resilience becomes essential to preserve resistance. A relational approach to the nonstatic nature of the interactions between resilience and resistance is productive insofar as it allows a broader view of resilience within the IR resilience literature.

\section{Acknowledgement}

For useful comments on previous versions of this article, we would like to thank Olaf Corry, Graham Denyer Willis, Ayse Zarakol, two anonymous reviewers, and the editors of the EJIR.

\section{Funding}

This research received no specific grant from any funding agency in the public, commercial or not-for-profit sectors.

\section{Notes}

1. We thank one reviewer for suggesting that we discuss this point.

2. We thank one reviewer for suggesting this.

3. Interview 4, Bethlehem, December 2011.

4. Interview 7, Bethlehem, December 2011.

5. Interview 2, Bethlehem, December 2011.

6. This in no way suggests that women are only ever still in the home while their husbands are in prison. There are also a substantial number of women who have been imprisoned during the course of the occupation.

7. Interview 5, Dheishah Refugee Camp, December 2011. 
8. Interview 13, Nabi Saleh, January 2012.

9. Interview 14, Nabi Saleh, January 2012.

10. Interview 13, Nabi Saleh, January 2012; Interview 14, Nabi Saleh, January 2012.

11. A petrochemical sprayed from a truck-mounted water cannon, 'skunk water' emits an extremely foul odour, which cannot be cleaned easily.

\section{References}

Abufarha N (2009) The Making of a Human Bomb: An Ethnography of Palestinian Resistance. Durham, NC: Duke University Press.

Al Haq (2011) Repression of non-violent protest in the Occupied Palestinian Territory: Case study on the village of Al-Nabi Saleh.

Amnesty International (2009) Troubled waters: Palestinians denied fair access to water.

Berkes F and Ross H (2013) Community resilience: Toward an integrated approach. Society \& Natural Resources 26(1): 5-20.

Bourbeau P (2013) Resiliencism: Premises and promises in securitization research. Resilience: International Policies, Practices and Discourses 1(1): 3-17.

Bourbeau P (2015a) Migration, resilience, and security: Responses to new inflows of asylum seekers and migrants. Journal of Ethnic and Migration Studies 41(12): 1958-1977.

Bourbeau P (2015b) Resilience and international politics: Premises, debates, agenda. International Studies Review 17(3): 374-395.

Boyd E and Folke C (2011) Adapting Institutions: Governance, Complexity and Social-Ecological Resilience. Cambridge: Cambridge University Press.

B'Tselem (2000) Thirsty for a solution: The water crisis in the Occupied Territories and its resolution in the final-status agreement.

Chandler D (2015) Resilience and the 'everyday': Beyond the paradox of 'liberal peace'. Review of International Studies 41(1): 27-48.

Chenoweth E and Stephan MJ (2011) Why Civil Resistance Works: The Strategic Logic of Nonviolent Conflict. New York, NY: Columbia University Press.

Corry O (2014) From defense to resilience: Environmental security beyond neo-liberalism. International Political Sociology 8(3): 256-274.

Davis D (2012) Urban Resilience in Situations of Chronic Violence. Final Report. Cambridge, MA: United States Agency for International Development and MIT Center for International Studies.

Duffield M (2012) Challenging environments: Danger, resilience and the aid industry. Security Dialogue 43(5): 475-492.

Dunn Cavelty M, Kaufmann M and Søby Kristensen K (2015) Resilience and (in)security: Practices, subjects, temporalities. Security Dialogue 46(1): 3-14.

Edwards P (2015) Closure through resilience: The case of Prevent. Studies in Conflict \& Terrorism 39(4): 1-37.

Emirbayer M (1997) Manifesto for a relational sociology. American Journal of Sociology 103: 281-317.

Evans B and Reid J (2013) Dangerously exposed: The life and death of the resilient subject. Resilience: International Policies, Practices and Discourses 1(2): 83-98.

Folke C (2006) Resilience: The emergence of a perspective for social-ecological systems analyses. Global Environmental Change 16: 253-267.

Foucault M, Burchell G, Gordon C and Miller P (1991) The Foucault Effect: Studies in Governmentality. Chicago: University of Chicago Press.

Hall PA and Lamont M (2013) Social Resilience in the Neoliberal Era. Cambridge: Cambridge University Press. 
Halper J (2006) A strategy within a non-strategy: Sumud, resistance, attrition and advocacy. Journal of Palestine Studies 35(3): 45-51.

Hasenclever A, Mayer P and Rittberger V (1997) Theories of International Regimes. Cambridge: Cambridge University Press.

Hass A (2002) Israel's closure policy: An ineffective strategy of containment and repression. Journal of Palestine Studies 31(3): 5-20.

Hillier D and Castillo GE (2013) No Accident: Resilience and the Inequality of Risk. London: Oxfam Briefing Papers.

Idler A, Belén Garrido M and Mouly C (2015) Peace territories in Colombia: Comparing civil resistance in two war-torn communities. Journal of Peacebuilding \& Development 10(3): $1-15$.

Jackson PT and Nexon DH (1999) Relations before states: Substance, process, and the study of world politics. European Journal of International Relations 5(3): 291-332.

Joseph J (2013a) Resilience as embedded neoliberalism: A governmentality approach. Resilience: International Policies, Practices and Discourses 1(1): 38-52.

Joseph J (2013b) Resilience in UK and French security strategy: An Anglo-Saxon bias? Politics 33(4): 253-264.

Khalili L (2007) Heroes and Martyrs of Palestine: The Politics of National Commemoration. Cambridge: Cambridge University Press.

Lentzos F and Rose N (2009) Governing insecurity: Contingency planning, protection, resilience. Economy and Society 38(2): 230-254.

Lepore SJ and Revenson TA (2006) Resilience and posttraumatic growth: Recovery, resistance, and reconfiguration. In: Calhoun LG and Tedeschi RG (eds) Handbook of Posttraumatic Growth: Research \& Practice. Mahmaw, NJ: Lawrence Erlbaum Associates Publishers.

Luthar SS (ed.) (2003) Resilience and Vulnerability: Adaptation in the Context of Childhood Adversities. Cambridge: Cambridge University Press.

Malkki L and Sinkkonen T (2015) Political resilience to terrorism in Europe: Introduction to the special issue. Studies in Conflict \& Terrorism 39(4): 281-91.

Masten AS and Cicchetti D (2016) Resilience in development: Progress and transformation. In: Cicchetti D (ed.) Developmental Pathopsychology. Volume 4. Risk, Resilience and Intervention. Hoboken: John Wiley \& Sons.

Parsons N and Salter M (2008) Israeli biopolitics: Closure, territorialisation and governmentality in the Occupied Palestinian Territories. Geopolitics 13(4): 701-723.

Pearlman W (2014) Violence, Nonviolence and the Palestinian National Movement. New York, NY: Cambridge University Press.

Richter-Devroe S (2011) Palestinian women's everyday resistance: Between normality and normalisation. Journal of International Women's Studies 12(3): 32-46.

Ruggie JG (1998) What makes the world hang together? Neo-utilitarianism and the social constructivist challenge (in constructivist approaches). International Organization 52(4): 855-885.

Rutter M (1987) Psychosocial resilience and protective mechanisms. American Journal of Orthopsychiatry 57: 316-331.

Ryan C (2015) Everyday resilience as resistance: Palestinian women practicing sumud. International Political Sociology 9(4): 299-315.

Schmidt J (2015) Intuitively neoliberal? Towards a critical understanding of resilience governance. European Journal of International Relations 21(2): 402-426.

Schock K (2005) Unarmed Insurrections: People Power Movements in Nondemocracies. Minneapolis, MN: University of Minnesota Press.

Schock K (2013) The practice and study of civil resistance. Journal of Peace Research 50(3): 277-290. 
Scott J (1985) Weapons of the Weak: Everyday Forms of Peasants Resistance. New Haven, CT: Yale University Press.

Scott JC (1990) Domination and the Arts of Resistance: Hidden Transcripts. New Haven, CT: Yale University Press.

Sending OJ, Pouliot V and Neumann IB (2015) Diplomacy and the Making of World Politics. Cambridge: Cambridge University Press.

Singh R (2012) The discourse and practice of 'heroic resistance' in the Israeli-Palestinian conflict: The case of Hamas. Politics, Religion \& Ideology 13(4): 529-545.

Sleijpen M, Ter Heide FJJ, Mooren T et al. (2013) Bouncing forward of young refugees: A perspective on resilience research directions. European Journal of Psychotraumatology 4: 201-24.

United Nations Office for the Coordination of Humanitarian Affairs Occupied Palestinian Territory (UNOCHAOPT) (2012) Humanitarian fact sheet on the Jordan Valley and the Dead Sea. East Jerusalem.

Van Teeffelen T (2011) Sumud: The Soul of the Palestinian People. Bethlehem: Arab Education Institute Open Windows. Available at: http://www.scribd.com/doc/101948051/Sumud-Soulof-Palestinian-People

Walker B, Holling CS, Carpenter SR et al. (2004) Resilience, adaptability and transformability in social-ecological systems. Ecology and Society 9(2). Available at: http://www.ecologyand society.org/vol9/iss2/art5/

Walker J and Cooper M (2011) Genealogies of resilience: From systems ecology to the political economy of crisis adaptation. Security Dialogue 42(2): 143-160.

Walklate S (2011) Reframing criminal victimization: Finding a place for vulnerability and resilience. Theoretical Criminology 15(2): 179-194.

Walsh F (2002) Bouncing forward: Resilience in the aftermath of September 11. Family Process 41(1): 34-36.

Walsh F (2003) Family resilience: A framework for clinical practice. Family Process 42(1): 1-18. Weizman E (2007) Hollow Land: Israel's Architecture of Occupation. London: Verso.

\section{Author biographies}

Philippe Bourbeau is Lecturer in the Department of Politics and International Studies at the University of Cambridge and a Research Fellow at Sidney Sussex College, UK. His research interests include international/global security, comparative immigration policies and resilience. He is the editor of Security: Dialogue across Disciplines (Cambridge University Press, 2015) and the author of The Securitization of Migration. A Study of Movement and Order (Routledge, 2011).

Caitlin Ryan is an Assistant Professor in International Security at the University of Groningen, Netherlands. She researches gender and security, specifically, how insecurities are produced, experienced and resisted. She has conducted research in Palestine and West Africa. Her book, Bodies, Power and Resistance in the Middle East, is published with Routledge and she has also published in International Political Sociology and Critical Studies on Security. 